\title{
Darcy Ribeiro: uma geração brasileira ${ }^{1}$
}

\author{
ÁNGEl RAMA \\ Crítico Uruguaio
}

ntre os importantes exilados brasileiros atualmente em nosso país, nenhum mais eminente na órbita da cultura, e igualmente não menos destacado entre nós que Darcy Ribeiro. Foi conhecido sobretudo por ter sido "Chefe da Casa Civil" da presidência da República e, pela mesma razão, por esse compadrio impune que usam alguns jornalistas para falar de políticos, se pôde vilipendiálo como as restantes figuras exiladas. Mas a real importância de Darcy Ribeiro, sem deixar de lado seu legado político, reside em sua obra de pedagogo e de antropólogo, integrando uma geração que no Brasil permitiu o amadurecimento das Ciências Sociais e tem dotado o país de um nível destacado no plano internacional.

Antes de ser Ministro da Educação (entre os anos 1962 e 1963), foi idealizador e primeiro reitor da Universidade de Brasília (anos 1957 a 1961) e já nessa data tinha dez anos de trabalho de campo em temas de Antropologia, tendo dedicado cinco deles para viver nas aldeias indígenas da Amazônia e do Mato Grosso, estudando "in loco" as culturas indígenas brasileiras em vias de desaparecimento.

Formado na "Escola de Sociologia e Política de São Paulo", integrante do "Museu do Índio" do Rio de Janeiro, no Departamento de Pesquisas

\footnotetext{
${ }^{1}$ RAMA, Ángel. "Darcy Ribeiro: una generación brasileña”. Entrevista de Darcy Ribeiro concedida a Ángel Rama. Marcha, Montevideo: 29 may. 1964. Texto traduzido por Haydée Ribeiro Coelho e revisada por Martha Muzio.

A entrevista em espanhol está publicada no livro. Las memorias de la memoria: el exilio de Darcy Ribeiro en Uruguay. COELHO, Haydée Ribeiro. (Org.). Entrevistas, Belo Horizonte: FALE/UFMG, 2003 e decorre do estágio de Pós-Doutorado em Montevidéu, março-julho, 2002, financiado pela CAPES.
} 
Etnológicas, sua dedicação às culturas indígenas, que o levou a percorrer o país e conviver com várias tribos distintas, começou a expressar-se por escrito desde que em 1950 publicou Religião e mitologia, ${ }^{2}$ estudo dedicado aos guaicurus, um grupo indígena do Pantanal brasileiro, que obteve por ocasião de seu aparecimento o prêmio "Fábio Prado de Ensaios". Livros posteriores recolhem assuntos de etnologia, arte, organização social dos índios e os problemas de assimilação. Entre eles se deve citar a Arte dos indios Kadiwéu e a Arte plumária consagrado aos índios do grupo tupi da Amazônia, que são os que conhecem melhor, e numerosos ensaios e artigos.

DARCY: Mas minha obra mais importante ainda não apareceu porque apesar de ter sido financiada pela UNESCO, e apesar de que em linhas gerais está concluída, e inclusive já traduzida para ser editada na França por Plon, nunca pude terminar de burilá-la. - disse-me no diálogo que mantivemos em seu pequeno apartamento montevideano.

ÁNGEL: De que se trata?

DARCY: É um livro sobre assimilação dos índios brasileiros, a cultura dos brancos, um livro que, em certo sentido, resume meus dez anos de estudos e pesquisas. Nunca dispus de três meses que necessitasse para completar o livro. Nunca pensei também que o exílio me concedesse esses meses.

ÁNGEL: O que ocorren a esses indios?

DARCY: Simplesmente estão sendo exterminados. Restam só seis mil índios no Brasil. Nos últimos sessenta anos têm desaparecido internamente oitenta e três grupos distintos com línguas, costumes, culturas, mitologias diferentes. Acredito que é um dos grandes dramas do mundo e da civilização. Se pensarmos que o mundo só registra umas duas mil culturas, a perda desse conjunto de culturas autóctones, originais, é realmente irreparável. Sem contar que nem sequer se tem conservado documentação sobre eles, sobre suas línguas e suas contribuições.

ÁNGEL: O estudo desses grupos é muito importante?

DARCY: Para meus alunos, costumava lhes dizer que facilmente podiam chegar à imortalidade.Se quiserem ser imortais, lhes dizia, tomem um desses grupos

\footnotetext{
${ }^{2}$ RIBEIRO, Darcy. Religião e Mitologia Kadiwéu. Rio de Janeiro: Conselho Nacional de Proteção aos Índios, 1950 .
} 
indígenas e dediquem-se a seu estudo. Seus nomes serão recordados sempre unidos a uma cultura que estamos vendo desaparecer sem fazer nada para salvá-la. Como etnólogos, como lingüistas, poderão alcançar mais facilmente à imortalidade, que como poetas ou cientistas. O que perdemos com essas culturas é imenso.

ÁNGEL: Que vinculo de trabalho têm tido com antropólogos europeus e americanos? Porque, paradoxalmente, eles são mais conhecidos entre nós que os brasileiros. Penso em Lévi-Strauss, em Métraux.

DARCY: São nossos amigos. Tanto os europeus como os americanos têm trabalhado solidariamente conosco. Charles Wegley, Robert Murphy, que pertencem ao Departamento de Pesquisas latino-americanas, da Universidade de Columbia, e também os franceses. Lévi-Strauss é dos mais competentes. Prezo nele, sobretudo, seus Tristes Trópicos, apesar de tratar-se de um simples livro de viagens. Há nele uma profunda compreensão humana. Métraux, por seu turno, deve-me seu primeiro conhecimento dos índios brasileiros. Apesar de ser um reconhecido especialista neles, nunca tinha convivido com os índios, só tinha conhecido alguns descendentes quando trabalhava em Rosário, Argentina. Bem que me odiou por isso! Organizamos-lhe uma viagem à Amazônia para que estivesse uns dias vivendo com uma das tribos mais aguerridas e duras. Como a viagem, por ferrovia, era muito longa, preferiu o avião que o deixava em um clarão da selva e que voltaria a recolhê-lo dias depois. Adiantou-se a estação de chuvas e durante dois meses foi impossível ir recolhê-lo. Não entendia a linguagem dos índios, não sabia o que fazer, com as mãos nas costas e a cabeça baixa dava voltas pelo acampamento, descobrindo que os índios o imitavam e caminhavam em fila atrás dele. Apesar disso, três dias depois de regressar, veio a abraçar-me e continuamos sendo grandes amigos.

ÁNGEL: Existe no Brasil, desde há anos, um intenso movimento renovador nas Ciências Sociais. Para caracterizá-lo conviria conhecer a opinião que tem esse movimento sobre Gilberto Freyre.

DARCY: É nosso pai, e por isso mesmo todos de minha geração odeiamno, esforçando-se por vencê-lo. Foi difícil superar a contribuição de Gilberto Freyre que tem as características fundamentais: $1^{\circ}$ absoluta desordem, assimetria metodológica, e $2^{\circ}$ uma extrema criatividade que the tem permitido grandes contribuições para a cultura brasileira e que em parte pode deverse a essa desordem intuitiva de sua criação. A maior contribuição que lhe 
devemos é ter sido o primeiro que conseguiu que o Brasil aceitasse sua ancestralidade negra e portuguesa. Contra todos aqueles que se envergonhavam dessa herança que os fazia descendentes de gente tão burra como os portugueses ou tão atrasada como os negros- assim diziam - Gilberto Freyre conseguiu impor o valor criativo da cultura negra e provar o colorido intenso que proporcionou ao Brasil . O mesmo com respeito aos portugueses. Seu último livro, Ordem e Progresso, é uma obra em vários volumes onde analisa a sociedade brasileira moderna do período republicano. Metodologicamente é muito superior a seus livros anteriores: realizou uma pesquisa paciente, entrevistando aqueles que viveram no período estudado. Mas em troca é inferior em intuições frutíferas.

ÁNGEL: Quais são aqueles que integram a nova geração?

DARCY: São dezenas de estudiosos. Poderia ser citado Sergio Buarque de Holanda, o melhor erudito brasileiro, dedicado à história social, autor de Raíes do Brasil e de um maravilhoso livro, Visão do Paraíso; pode ser mencionado Florestan Fernandes, a principal revelação dos últimos anos de metodologia das Ciências Sociais ; Luís Costa Pinto, cuja obra já tem sido traduzida em espanhol, um sociólogo combativo, inteligente, que tem encarado a Sociologia como instrumento de penetração e ação na realidade brasileira, Víctor Nunes Leal, voltado para o estudo do colonialismo.

ÁNGEL: Em Ciências Literárias?

DARCY: Em primeiro destaque Antonio Candido e, junto a ele, Heron Alencar (formado na Bahia, leitor durante muitos anos na Sorbonne) e Helcio Martins, da escola do Rio de Janeiro, aqueles que se têm dedicado à Teoria literária, tratando de colocar estes estudos em um quadro geral da cultura brasileira, reconhecendo sua implantação ativa e dinâmica no seio da sociedade.

ÁNGEL: Essa geração emergiu dos anos 50, e o que parece foi dominada por uma orientação universitária. Como poderia ser caracterizado globalmente o movimento?

DARCY: Creio que é a melhor geração que deu ao país a mais lúcida, com mais rigorosa consciência crítica e aquela mais comprometida na luta transformadora da nacionalidade. Em Ciências Sociais, a linha dominante é a universitária. Todos seu integrantes há anos ocupam cátedras e têm já numerosos discípulos, ampliando assim a órbita de sua ação no meio.Têm partido de uma visão nacional, a primeira que registra o país, substituindo aquela dos europeizados que escreviam livros com base em teorias estrangeiras 
para serem aceitas por estrangeiros. Têm assumido uma consciência crítica da realidade brasileira, e, ao mesmo tempo, têm pretendido fazer das Ciências Sociais não tarefas puramente especulativas, acadêmicas, senão instrumentos de ação sobre a vida social .

ÁNGEL: Tem sido positiva sua ação?

DARCY: Profundamente positiva. Permitiu criar um produto cultural próprio,original. Seus integrantes interessaram-se pelos fatos do mundo circundante, e por isso mesmo têm ficado isentos da enfermidade mais grave da vida intelectual...

ÁNGEL: Que é qual?

DARCY: A de converter a cultura em um elemento de gozo, de fruição, utilizando-a como meio para um afastamento da realidade.

ÁNGEL: Em matéria de ideologias, o marxismo tem tido influência na formação do movimento?

DARCY: Pode-se dizer que este tem tido, de comum com o marxismo, o critério do interesse prático, ou seja, que o saber é necessário para atuar, mas esse legado marxista ficou englobado na mais vasta e rica da escola moderna de Ciências Sociais, em boa parte sob a influência francesa, e, a partir do fim da guerra por obra da escola anglo-norte-americana.

ÁNGEL: Que influência tem tido sobre os aspectos concretos da vida brasileira, politica, social, cultural?

DARCY: Toda solução dos problemas brasileiros está baseada nesses estudos, prévios para uma consideração real e firme de nossa situação. Seus autores, por outro lado, sempre tiveram uma participação concreta no exame das soluções. Meu caso particular, de ingresso à atividade política pode estar motivado por razões pessoais de maior combatividade, mas penso que qualquer desses intelectuais, se fosse chamado a desempenhar uma tarefa pública, a assumiria de conformidade com o que têm estudado e o que têm ensinado sobre o Brasil.

ÁNGEL: Qual é o futuro dessa corrente?

DARCY: Vai promover a existência de uma cultura brasileira, e vai apresentála como cultura própria aos olhos do mundo. Luta para construir os instrumentos com que realizar uma obra regida pelo interesse nacional, pela aceitação da própria realidade, pelo desejo de transformá-la. Padecemos de terríveis deficiências.Basta assinalar que em um país de 80 milhões de habitantes só 20 têm acesso à expressão cultural e podem contribuir para o desenvolvi- 
190 VIAATLÂNTICA N 8 DEZ/2005

mento do país porque são os únicos que podem ser educados. Isso não ocorre na França, onde qualquer cidadão tem grandes opções por seus méritos. Conseguir uma integração cultural da nacionalidade é um dos propósitos básicos desse movimento cultural brasileiro. 